\title{
Redescription of Metabronema magnum (Nematoda: Cystidicolidae), a swimbladder parasite of the carangid fish Gnathanodon speciosus off New Caledonia
}

\author{
František Moravec $^{1}$ and Jean-Lou Justine ${ }^{2}$
}

${ }^{1}$ Institute of Parasitology, Biology Centre, Academy of Sciences of the Czech Republic, Branišovská 31, 37005 České Budějovice, Czech Republic;

${ }^{2}$ Équipe Biogéographie Marine Tropicale, Unité Systématique, Adaptation, Évolution (UPMC, CNRS, MNHN, IRD), Institut de Recherche pour le Développement, BP A5, 98848 Nouméa Cedex, New Caledonia

Key words: parasitic nematode, Metabronema, morphology, marine fish, Gnathanodon, New Caledonia

\begin{abstract}
The cystidicolid nematode Metabronema magnum (Taylor, 1925) is redescribed from specimens collected from the swimbladder of the fish (golden trevally) Gnathanodon speciosus (Forsskål) (Carangidae, Perciformes) off New Caledonia, South Pacific (a new geographical record). The light and scanning electron microscopical examination made it possible to study in detail the morphology of this so far little-known species. Its pseudolabia were found to possess distinct anterior protrusions (protuberances), sublabia are absent, only four cephalic papillae are present, deirids are bifurcated, and the male possesses six pairs of postanal papillae. By its morphology, M. magnum seems to be most similar to species of Salvelinema Trofimenko, 1962, also from the swimbladder of fishes, differing from them mainly in the presence of median wedge-shaped outgrowths in the mouth, lateral alae, the longer spicule on the right side, and a fewer number of pairs of preanal papillae in the male. Since the morphology of M. magnum considerably differs from that of other representatives of the Cystidicolidae, Metabronema in Rasheed's (1966) conception is considered a valid genus.
\end{abstract}

The present taxonomy of cystidicolid nematodes remains rather confused, because several genera have been based on details in the cephalic structures visible only with the aid of scanning electron microscopy (SEM); however, it is not evident whether these tiny features are of generic importance unless more cystidicolids are described using SEM and comparative molecular data become available (Ferrer et al. 2005, Moravec et al. 2006, 2007, Moravec and González-Solís 2007, Moravec and Klimpel 2007).

In October 2006, a sample of marine fishes was obtained from the fish market in Nouméa, New Caledonia. Two examined specimens of the carangid fish (golden trevally) Gnathanodon speciosus (Forsskål) were found to harbour in their swimbladders hitherto little-known nematodes Metabronema magnum (Taylor, 1925), the type species of the monotypic genus Metabronema Yorke et Maplestone, 1926. The last record of M. magnum dates back fifty years ago from G. speciosus off Australia (Mawson 1957). Margolis (1977) mentioned that he had studied the cephalic structure of Metabronema by SEM, but his results had not been published; probably two of his scanning electron micrographs of the anterior extremity of $M$. magnum were later used in the paper by Ko et al. (1985). New observations on the morphology (including SEM) of this remarkable nematode species, based on the New Caledonian material, are presented herein.

\section{MATERIALS AND METHODS}

Two specimens of the golden trevally, Gnathanodon speciosus (Forsskål) (fork length of body of both $24 \mathrm{~cm}$ ), were obtained from the fish market in Nouméa, New Caledonia, on 4 October 2006; they were kept on ice. These were immediately examined for the presence of helminth parasites in the IRD laboratory in Nouméa. For morphological studies, the living nematodes recovered from the fish swimbladders were fixed in a hot $4 \%$ formaldehyde solution. For light microscopical examination, nematodes were cleared with glycerol. Drawings were made with the aid of a Zeiss microscope drawing attachment. Specimens used for scanning electron microscopy were postfixed in $1 \%$ osmium tetroxide, dehydrated through a graded acetone series, critical point dried and sputter-coated with gold; they were examined using a JEOL JSM6300 scanning electron microscope at an accelerating voltage of $15 \mathrm{kV}$. All measurements are in micrometres unless otherwise stated. Fish names follow FishBase (Froese and Pauly 2007).

\section{DESCRIPTION}

Metabronema magnum (Taylor, 1925) Yorke et Maplestone, 1926

Figs. 1-4

Syn.: Habronema magnum Taylor, 1925; Metabronema carangis Tubangui et Masiluñgan, 1938.

General: Large, whitish nematodes with thick, densely transversely striated cuticle (Figs. 3D, F, 4D).

Address for correspondence: F. Moravec, Institute of Parasitology, Biology Centre, Academy of Sciences of the Czech Republic, Branišovská 31, 37005 České Budějovice, Czech Republic. Phone: ++420 387775 432; Fax: ++420 385 310 388; E-mail: moravec@paru.cas.cz 


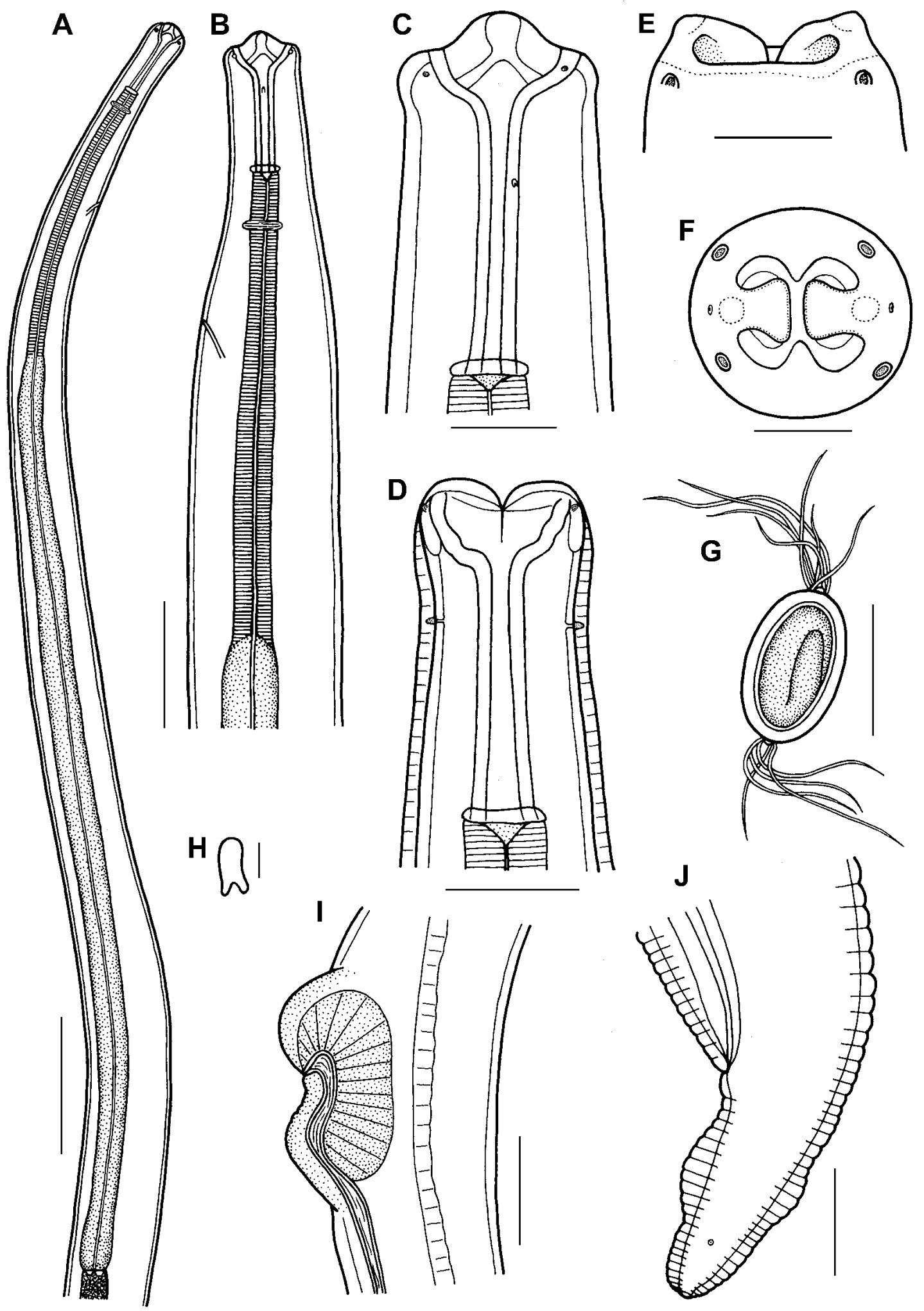

Fig. 1. Metabronema magnum (Taylor, 1925). A - oesophageal part of male body, lateral view; B - anterior part of body of nongravid female, lateral view; $\mathbf{C}, \mathbf{D}$ - anterior end of nongravid female, lateral and dorsoventral views; $\mathbf{E}, \mathbf{F}-$ cephalic end of gravid female, dorsoventral and apical views (reconstructed from scanning electron micrographs); $\mathbf{G}$ - fully developed egg; $\mathbf{H}$ - deirid, lateral view; I - region of vulva of nongravid female, lateral view; $\mathbf{J}$ - tail of gravid female, lateral view. Scale bars: $\mathrm{A}, \mathrm{I}=500 \mu \mathrm{m} ; \mathrm{B}=300 \mu \mathrm{m} ; \mathrm{C}, \mathrm{D}=100 \mu \mathrm{m} ; \mathrm{E}, \mathrm{F}=40 \mu \mathrm{m} ; \mathrm{G}=30 \mu \mathrm{m} ; \mathrm{H}=2 \mu \mathrm{m} ; \mathrm{J}=200 \mu \mathrm{m}$. 

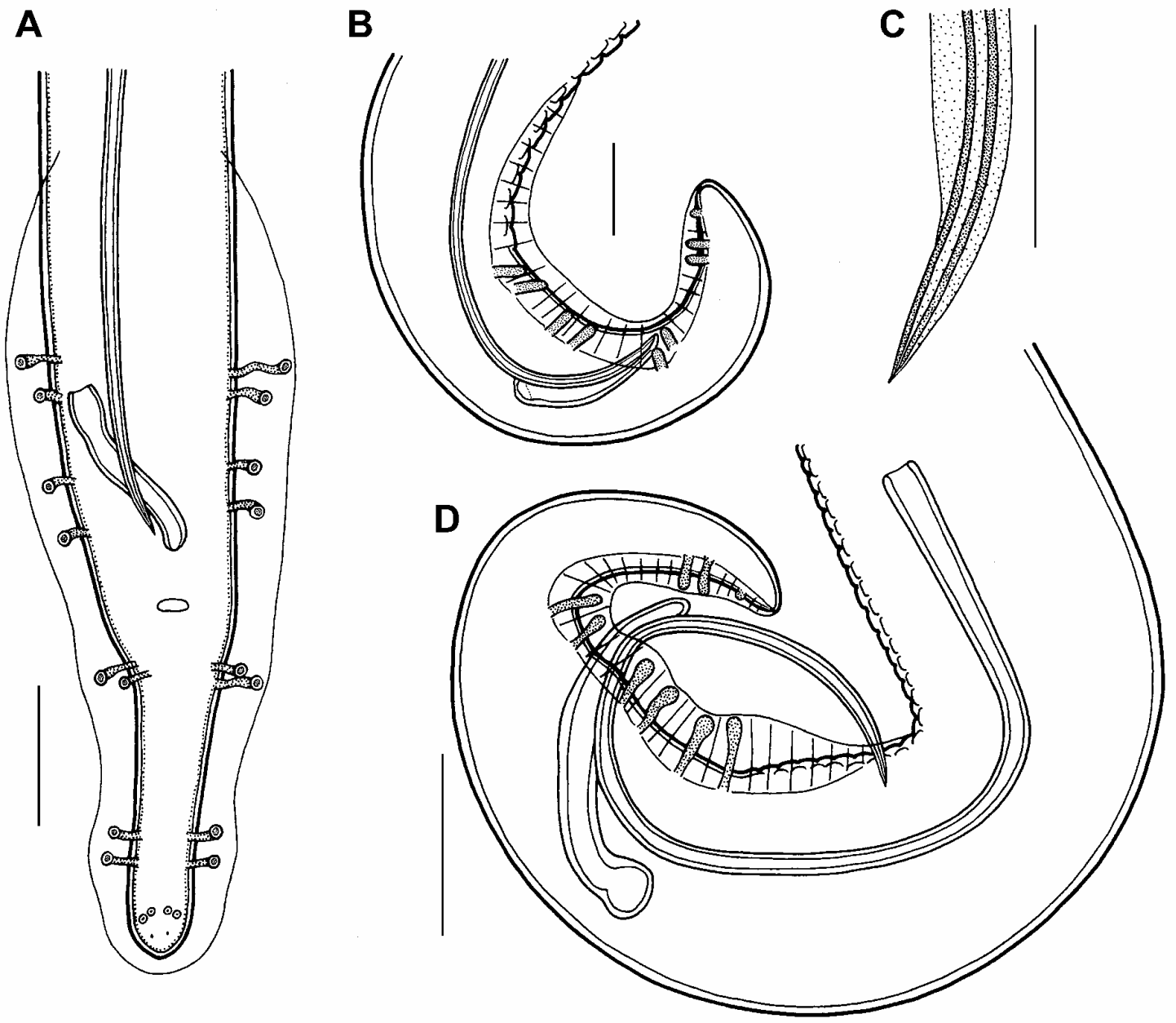

Fig. 2. Metabronema magnum (Taylor, 1925). A, B - caudal end of young male, ventral and lateral views; C - distal end of long spicule, lateral view; D - caudal end of larger male, lateral view. Scale bars: A, B $=100 \mu \mathrm{m} ; \mathrm{C}=50 \mu \mathrm{m} ; \mathrm{D}=200 \mu \mathrm{m}$.

Body tapering at both ends. Two thick, narrow lateral alae extending from level of prostom to that of anterior ends of subventral caudal alae in male and somewhat posterior to anus in female (Figs. 1D, 3E, 4B, D). Cephalic end rounded, with two large, relatively broad, anteriorly protruding pseudolabia (Figs. 1C-F, 3A-C). Oral aperture large, almost circular, surrounded by four small submedian cephalic papillae and pair of lateral amphids (Figs. 1F, 3A-C). Pseudolabia strengthened internally with heavily sclerotized, Y-shaped structure in lateral view, both arms of which being attached to wall of prostom (Fig. 1C). Each pseudolabium provided with distinct rounded anterior protrusion (protuberance) at its base (Figs. 1E, F, 3A-C). In apical view, flat inner parts of pseudolabia partly cover mouth and are somewhat dorsoventrally expanded, forming two (1 dorsolateral and 1 ventrolateral) extensions on each; inner margins of both pseudolabia dorsoventrally straight, parallel to each other (Figs. 1F, 3A). Two small, median (1 dorsal and 1 ventral) wedge-shaped outgrowths of mouth wall present between outer edges of two lateral pseudolabia (Figs. 1F, 3A, B). Vestibule (stoma) thickwalled, divided into anterior, well-developed prostom and posterior, narrower cylindrical part; base of vestibule forming large, transverse sclerotized ring on anterior end of oesophagus (Fig. 1C, D). Muscular oesophagus short, narrow, cylindrical, glandular oesophagus somewhat broader, approximately 3-9 times longer than muscular one (Fig. 1A). Nerve ring encircling muscular oesophagus near its anterior end. Excretory pore at about level of anterior third of muscular oesophagus. Deirids small, with bifurcated tip, situated short distance posterior to prostom (Figs. 1B-D, H, 3D). Tail of both sexes conical, with rounded end.

Male (5 specimens; measurements of 1 juvenile specimen in parentheses): Length of body 13.59-22.70 (10.13) mm, maximum width 367-653 (258). Height of pseudolabia 18-33 (15). Length of entire vestibule including prostom 243-303 (213); prostom 39-51 (36) long, 81-126 (81) wide in lateral view, thickness of its wall 9-15 (9). Muscular oesophagus 789-1,142 (not measured) long and 63-78 (-) wide; glandular oesopha- 

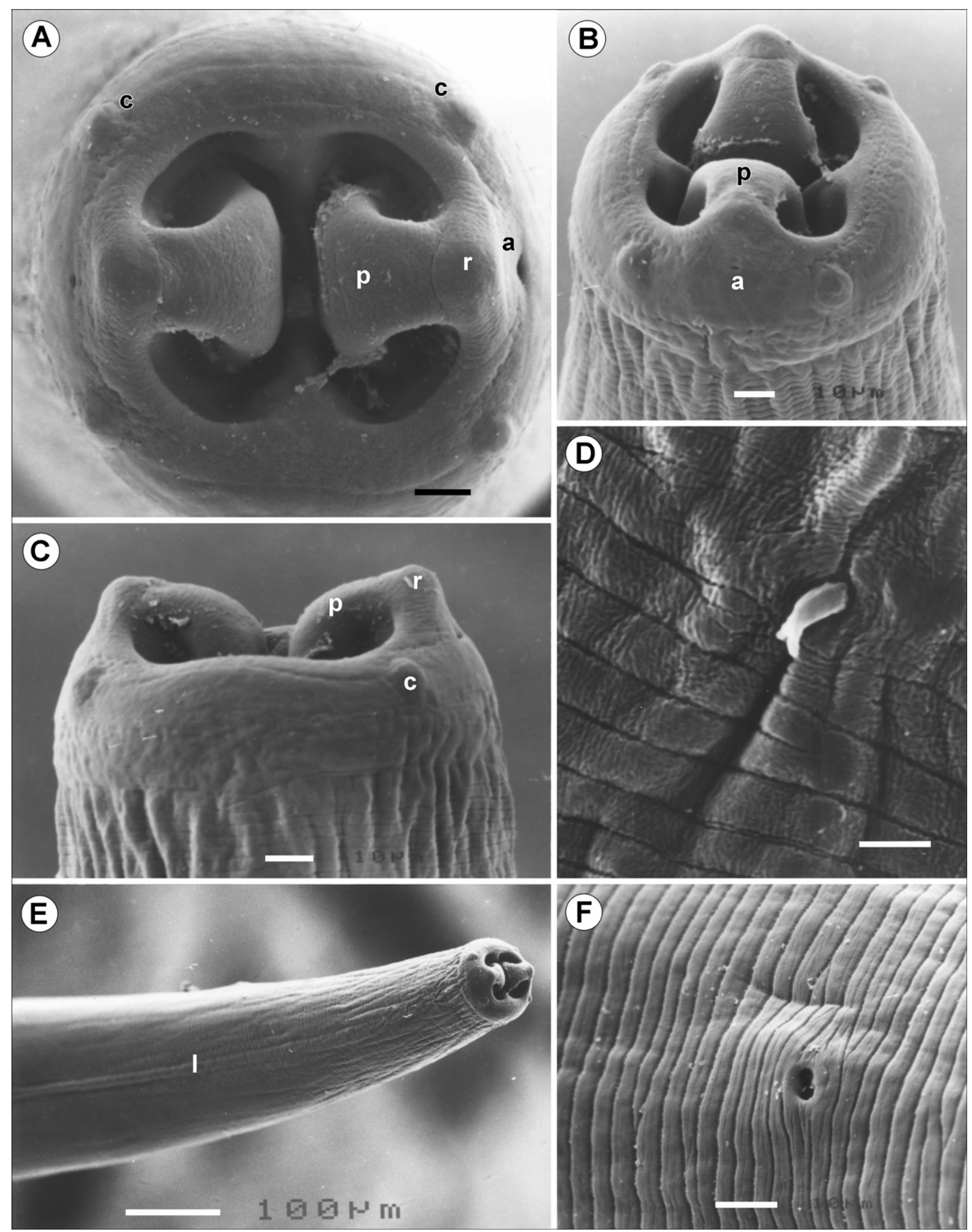

Fig. 3. Metabronema magnum (Taylor, 1925), scanning electron micrographs. A - cephalic end, apical view; $\mathbf{B}$ - cephalic end, lateral view; C - cephalic end, dorsoventral view; D - deirid, sublateral view; $\mathbf{E}$ - anterior end of body, lateral view; $\mathbf{F}$ - striation of cuticle in region of excretory pore, ventral view. Abbreviations: a - amphid; c - cephalic papilla; 1 - lateral ala; $p$ - pseudolabium; $\mathrm{r}$ - pseudolabial protuberance. Scale bars: $\mathrm{A}=10 \mu \mathrm{m} ; \mathrm{D}=3 \mu \mathrm{m}$. 
gus 2.61-4.22 (-) mm long, 96-201 (-) in maximum width; length ratio 1:2.9-4.5 (-). Deirids, nerve ring and excretory pore 102-141 (96), 340-476 (-) and 503-680 (503), respectively, from anterior extremity. Caudal alae and ventral precloacal tessellated cuticular ridges (area rugosa) well developed (Figs. 2A-D, 4C); latter consisting of about 19 longitudinal rows of ridges. Preanal papillae: 4 pairs of subventral pedunculate papillae present, arranged more or less in two couples. Postanal papillae: 5 pairs of subventral and 1 pair of ventral papillae present, of which anterior 4 pairs of subventrals pedunculate, arranged in two couples; last pair of subventrals formed by small sessile papillae; ventral papillae small, sessile, situated approximately at level of last pair of subventrals (Figs. 2A, 4E, F). Phasmids very small, situated posterior to last pair of subventral postanal papillae (Fig. 4E). Right spicule slender, 1.061.67 (1.11) mm long; proximal end of spicule somewhat broader, distal end sharply pointed (Fig. 2C). Left spicule short, boat-shaped, 129-495 (135) long; its proximal end blunt, distal end rounded, with narrow membranous cover. Length ratio of spicules 1:2.7-8.2. Tail 180-326 (213) long, with rounded tip.

Female (1 gravid specimen with mature eggs; measurements of 3 nongravid specimens in parentheses): Length of body 73.35 (20.93-47.95) mm, maximum width 898 (382-544). Height of pseudolabia 39 (15$39)$. Length of entire vestibule including prostom 422 (285-326); prostom 84 (48-51) long, 198 (99-147) wide in lateral view. Muscular oesophagus 1.65 (0.95$1.29) \mathrm{mm}$ long, 163 (68-109) wide; glandular oesophagus 11.26 (2.79-11.49) mm long, 408 (109-218) in maximum width; length ratio 1:6.8 (1:2.7-8.9). Deirids, nerve ring and excretory pore 201 (114-174), 598 (381598 ) and 898 (558-775), respectively, from anterior extremity. Tail 476 (245-326) long, with rounded tip (Fig. 1J). In addition to transverse striations, cuticle of posterior part of body, particularly that of tail, has small raised portions more or less oblong in shape (Fig. 4A, B). Vulva in anterior half of body, 24.21 (10.88-17.00) from anterior extremity, 33\% (36-49\%) of body length; vulval lips large, elevated. Vagina narrow, directed posteriorly from vulva, its distal part with large oval ovijector (Fig. 1I). Uterus amphidelphic. Fully developed eggs oval, thick-walled, larvated, size $42-48 \times 24$ $(\mathrm{n}=3)$; each pole of egg with small polar knob and group of 5-7 fine, thread-like filaments up to 50 long (Fig. 1G).

H o s t : Golden trevally, Gnathanodon speciosus (Forsskål) (Carangidae, Perciformes) (body length $24 \mathrm{~cm}$ ). Previously also reported from perciform fishes Caranx sexfasciatus Quoi et Gaimard and Trachurus declivis (Jenyns) (both Carangidae), and Sparus sp. (Sparidae) (Taylor 1925, Parukhin 1975).

Site of infection: Swimbladder.

L o c a 1 i t y : Fish market at Nouméa, New Caledonia (collected 4 October 2006).
Prevalence and intensity: In 2 specimens of $G$. speciosus examined, 7 and 13 nematodes were found.

Deposition of voucher specimens: Muséum National d'Histoire Naturelle, Paris (Cat. No. JNC 1987) and Institute of Parasitology, Biology Centre of the ASCR, České Budějovice (Cat. No. N-871).

\section{DISCUSSION}

The general morphology of nematodes of the present material is, more or less, in agreement with the descriptions of Metabronema magnum (Taylor, 1925), as provided by Taylor (1925), Tubangui and Masiluñgan (1938), Mawson (1957) and Rasheed (1966). Although Taylor (1925) reported the presence of a gubernaculum in the original description of M. magnum (reported as Habronema magna [sic]), this was neither confirmed by Rasheed (1966) in the re-examined types nor observed by Baylis (1934), Tubangui and Masiluñgan (1938) and Mawson (1957) in later collected specimens. Since Gnathanodon speciosus is named among the hosts of $M$. magnum in the nearby region (Australia), there is little doubt that the present New Caledonian specimens belong to this species.

The SEM examination showed some taxonomically important, not previously reported features. The pseudolabia were found to bear distinct anterior protrusions (protuberances) on their basal parts (Fig. 3A, C); the presence of such pseudolabial protrusions (weakly or highly developed) is also characteristic of members of some other cystidicolid genera such as Ascarophis van Beneden, 1871, Comephoronema Layman, 1933, Cystidicola Fischer, 1798, Cystidicoloides Skinker, 1931 or Neoascarophis Machida, 1976 (e.g., Appy 1981, Ko 1986, Moravec and Rokicki 2002, Frantová and Moravec 2003, Ferrer et al. 2005, Moravec et al. 2006, Moravec and González-Solís 2007, Moravec and Klimpel 2007), but these are absent from species of others. The shape of pseudolabia (in an apical view) of $M$. magnum also resembles those of some species in other cystidicolid genera. On the other hand, sublabia or submedian sclerotized plates described in members of $\mathrm{As}$ carophis, Comephoronema, Cystidicoloides and some other genera are absent in Metabronema. However, a unique feature of $M$. magnum is the presence of median wedge-shaped outgrowths of the mouth wall (Fig. 3A, B), by which this species markedly differs from members of other related genera. Rasheed (1966) illustrated four pairs of cephalic papillae in M. magnum, but only four single papillae were found by SEM in this study (Fig. 3A, B).

Until recently, little attention was paid to the shape of deirids in this nematode group, but Ferrer at al. (2005), Moravec et al. (2006) and Moravec and Klimpel (2007) pointed out that it might be a reliable taxonomic feature in cystidicolids. As in Metabronema (Fig. 3D), bifurcated deirids were also found in some Ascarophis, 

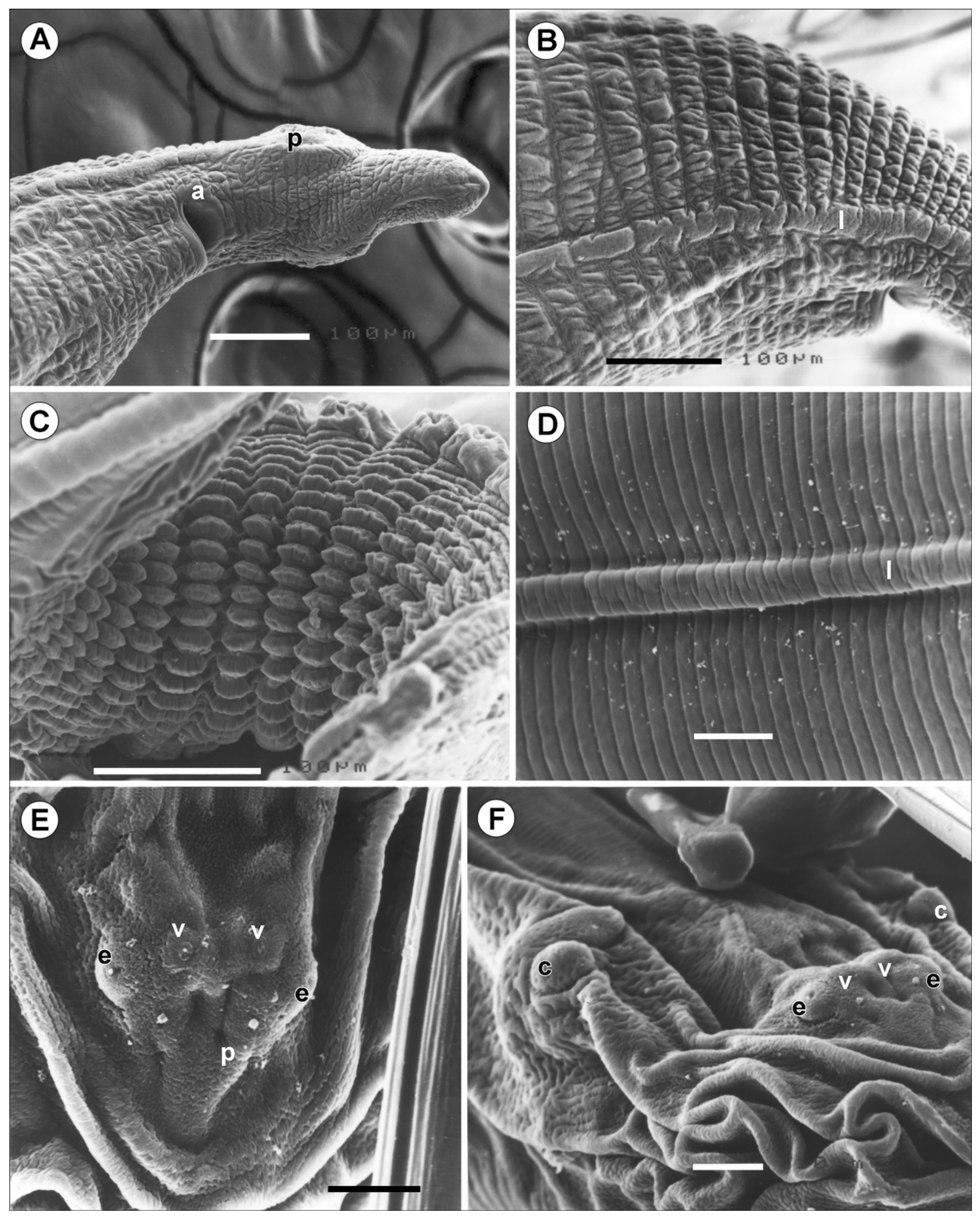

Fig. 4. Metabronema magnum (Taylor, 1925), scanning electron micrographs. A - tail of gravid female, ventral view; B - detail of caudal region of gravid female with distinct transverse striae, lateral ala and superficial formations on cuticle, lateral view; C - ventral precloacal tessellated ridges on male caudal end, ventral view; D - lateral ala at middle part of body, lateral view; $\mathbf{E}, \mathbf{F}$ - arrangement of posterior two pairs of caudal papillae on male tail, ventral and sublateral views. Abbreviations: a - anus; $\mathrm{c}$ - subventral papilla of last but one pair; e - subventral papilla of last pair; 1 - lateral ala; $p$ - phasmid; $v$ - ventral papilla. Scale bars: $\mathrm{D}=20 \mu \mathrm{m} ; \mathrm{E}, \mathrm{F}=10 \mu \mathrm{m}$. 
Comephoronema and Neoascarophis species (Ferrer et al. 2005, Moravec et al. 2006, Moravec and Klimpel 2007). A characteristic feature of Metabronema is the presence of lateral alae, which generally do not occur in cystidicolids, except for members of Ctenascarophis Mamaev, 1968 (see Crites et al. 1993). The ornamentations of the cuticle of older females seem to be characteristic of Metabronema only. Taylor (1925) and Rasheed (1966) reported the presence of two fine filaments on each egg pole in $M$. magnum, whereas, two or more filaments on each pole were observed by Tubangui and Masiluñgan (1938). In the present material, 5-7 filaments on each pole of the fully developed eggs (containing a larva) of $M$. magnum were found.

In the original description of M. magnum, Taylor (1925) reported five pairs of male postanal papillae, the last one of which being formed by "two broad sessile papillae, each carrying three points"; five pairs of postanal papillae in this species were also reported by Rasheed (1966), Tubangui and Masiluñgan (1938) and Mawson (1957). However, the scanning electron micrographs show that six pairs of postanal papillae are present and that, in addition to five subventral papillae, there is a pair of ventral papillae situated at the level of the last subventrals, being followed by a pair of minute phasmids (Fig. 4E, F). Such an arrangement of the last pairs of postanal papillae is typical of most cystidicolids.

Metabronema magnum was originally described by Taylor (1925) as Habronema magna [sic] from specimens collected by P.A. Maplestone from the swimbladder of the greenback horse mackerel Trachurus declivis (Jenyns) in Australia; four damaged females were also recorded from the sub-peritoneum of Sparus sp. Subsequently, Yorke and Maplestone (1926) created a new monotypic genus Metabronema to accommodate this species, but Chitwood and Wehr (1934) considered Metabronema a synonym of Ascarophis van Beneden, 1871.

On the contrary, Baylis (1934), who had studied $M$. magnum specimens from the swimbladder of the golden trevally Gnathanodon speciosus from Queensland, Australia, took Metabronema for a valid genus. He considered it to be closer to Cystidicola Fischer, 1798 than to Habronema Diesing, 1861, finding differences between Metabronema and Cystidicola in the structure of the male caudal ends only. Baylis (1934) also synonymized Cystidicoloides Skinker, 1931 with Metabronema, so that many species of this genus were assigned by him and subsequent authors to Metabronema.

Tubangui and Masiluñgan (1938) described a new species, Metabronema carangis (reported incorrectly as M. caranxi [sic]) from Gnathanodon speciosus (as $\mathrm{Ca}$ ranx speciosus) from the Philippines (Luzon), distinguishing it from $M$. magnum principally by the absence of a gubernaculum, a somewhat shorter right spicule and slightly larger eggs. However, $M$. carangis was synonymized with M. magnum by Rasheed (1966) (see also Arthur and Lumanlan-Mayo 1997), because the above-mentioned differences were either due to inexact observations or are within an intraspecific variability of this species (see Baylis 1934, Mawson 1957, Rasheed 1966 , present data). Based on a re-examination of the type specimens of M. magnum, Rasheed (1966) correctly pointed out that the morphology of this species was very different from that of other species in this genus (see above) and, consequently, she redefined Metabronema as a monotypic genus. Later Kataitseva (1979) described an additional species of Metabronema from the stomach of Polymixia japonica Günther (silver eye) (Polymixiidae, Polymixiiformes) from the Philippines; because its name was written only in a Cyrillic alphabet (later transcribed as M. polymiksiae Kataitseva, 1979 by Arthur and Lumanlan-Mayo 1997), this name is unavailable according to the International Code of Zoological Nomenclature (Article 11.2, 11.5, 11.6); judging from the description (a single female available), illustrations and the site of infection in the host, this was probably an Ascarophis-like nematode.

The only other records of M. magnum were those by Mawson (1957) from Gnathanodon (as Caranx) speciosus at Heron Island, off the Queensland coast in Australia and by Parukhin (1975) from Caranx sexfasciatus Quoi et Gaimard from the Monar Bay, Indian Ocean. Mawson (1957) mentioned that this species was a common swimbladder parasite of these fish, with the mean intensity of about six parasites per fish. The present finding suggests that M. magnum is a frequent parasite of G. speciosus also in New Caledonian waters, from where it is now reported for the first time.

The general morphology of $M$. magnum indicates that it differs considerably from that of other cystidicolids and that Metabronema in Rasheed's (1966) conception is a valid genus. It has been mentioned above that Baylis (1934) considered Metabronema to be close to Cystidicola; in fact, it seems to be more similar to Salvelinema Trofimenko, 1962 (see Moravec and Nagasawa 1999). Nevertheless, representatives of all these three genera have no sublabia, they possess filamented eggs, and their adults are swimbladder parasites. Metabronema differs from both Cystidicola and Salvelinema mainly in the presence of lateral alae, median wedgeshaped outgrowths in the mouth, fewer pairs of preanal papillae, and a longer right than left spicule; from $C y s$ tidicola also in the absence of teeth and submedian lips in the mouth and the presence of deirids. Phylogenetic relationships of Metabronema will be clearer when $M$. magnum and representatives of other cystidicolid genera are examined by molecular methods.

Acknowledgements. Thanks are due to the staff of the Laboratory of Electron Microscopy of the Institute of Parasitology, Biology Centre of the ASCR, in České Budějovice for their technical assistance and Irena Husáková from the Department of Helminthology of the same Institute for her help with the preparation of illustrations. This study was partly supported by grant no. 524/06/0170 from the Grant Agency of the Czech Republic and by the research projects of the Institute of Parasitology, ASCR (Z60220518 and LC522). 


\section{REFERENCES}

APPY R.G. 1981: Species of Ascarophis van Beneden, 1870 (Nematoda: Cystidicolidae) in North Atlantic fishes. Can. J. Zool. 59: 2193-2205.

ARTHUR J.R., LUMANLAN-MAYO S. 1997: Checklist of the Parasites of Fishes of the Philippines. FAO Fish. Tech. Paper. No. 369. FAO, Rome, $102 \mathrm{pp}$.

BAYLIS H.A. 1934: Three helminthological notes. Ann. Mag. Nat. Hist., Ser. 10, 14: 115-121.

CHITwOOD B.G., WEHR E.E. 1934: The value of cephalic structures as characters in nematode classification, with special reference to the superfamily Spiruroidea. Z. Parasitenkd. 7: 273-335.

Crites J.L., Overstreet R.M., Maung M. 1993: Ctenascarophis lesteri n. sp. and Prospinitectus exiguus n. sp. (Nematoda: Cystidicolidae) from the skipjack tuna, Katsuwonus pelamis. J. Parasitol. 79: 847-859.

Ferrer E., Aznar F.J., Balbuena J.A., Kostadinova A., RAGA J.A., MORAVEC F. 2005: A new cystidicolid nematode from Mullus surmuletus (Perciformes: Mullidae) from the western Mediterranean. J. Parasitol. 91: 335-344.

FRANTOVÁ D., MORAVEC F. 2003: Ultrastructure of the body wall of Cystidicoloides ephemeridarum (Nematoda, Cystidicolidae) in relation to the histopathology of this nematode in salmonids. Parasitol. Res. 91: 100-108.

Froese R., PAuly D. (Eds.) 2007: FishBase. World Wide Web electronic publication, www.fishbase.org, version 01/2007.

KATAITSEVA T.V. 1979: [A new species of nematode of the genus Metabronema (Nematoda, Spirurata) from the stomach of fish of the Philippine Sea.] Tr. Uzb. Nauchno-Issled. Vet. Inst. 29: 59-61. (In Russian.)

Ko R.C. 1986: A Preliminary Review of the Genus Ascarophis van Beneden, 1871 (Nematoda: Cystidicolidae) of the Gastrointestinal Tract of Fishes. Occas. Publ., Department of Zoology, University of Hong Kong, 54 p.

Ko R.C., Margolis L., MACHIDA M. 1985: Pseudascarophis kyphosi n. gen., n. sp. (Nematoda: Cystidicolidae) from the stomach of the fish Kyphosus cinerascens (Forskål) [sic] from Japan. Can. J. Zool. 63: 2684-2688.

MARGOLIS L. 1977: Caballeronema gen. nov. for Metabronema wardlei Smedley, 1934 (Nematoda, Spiruroidea) from the marine fish Scorpaenichthys marmoratus from the Pacific coast of Canada. Excerta Parasitológica en memoria del doctor Eduardo Caballero y Caballero, Instituto de Biología, Univer-

Received 7 February 2007 sidad Nacional Autónoma de México, Publicaciones especiales 4, pp. 447-454.

MAWSON P.M. 1957: Some nematodes from fish from Heron Island, Queensland. Trans. R. Soc. S. Australia 80: 177-179.

MorAVEC F., GONZÁLEZ-Solís D. 2007: Structure of the cephalic end of Ascarophis mexicana (Nematoda: Cystidicolidae), as revealed by SEM. Folia Parasitol. 54: 155-156.

MORAVEC F., HANZELOVÁ V., GERDEAUX D. 2007: New data on the morphology of Comephoronema oschmarini (Nematoda: Cystidicolidae), a little-known gastrointestinal parasite of Lota lota (Teleostei) in Palaearctic Eurasia. Acta Parasitol. 52: $135-141$.

MoRAVEC F., KLIMPEL S. 2007: A new species of Comephoronema (Nematoda: Cystidicolidae) from the stomach of the abyssal halosaur Halosauropsis macrochir (Teleostei) from the Mid-Atlantic Ridge. J. Parasitol. 93: 901-906.

MORAVEC F., KLIMPEL S., KARA E. 2006: Neoascarophis macrouri n. sp. (Nematoda: Cystidicolidae) from the stomach of Macrourus berglax (Macrouridae) in the eastern Greenland Sea. Syst. Parasitol. 63: 231-237.

MoraVEC F., NAGASAWA K. 1999: Morphology and taxonomy of Salvelinema species (Nematoda: Cystidicolidae), swimbladder parasites of Pacific area salmonids. Folia Parasitol. 46: $123-131$.

MORAVEC F., ROKICKI J. 2002: Some new data on the morphology of Cystidicola farionis (Nematoda, Cystidicolidae), a swimbladder parasite of salmonids, as revealed by SEM. Acta Parasitol. 47: 29-33.

PARUKHIN A.M. 1975: [On distribution in the World Ocean of Nematoda found in fish from the southern seas.] Vest. Zool. 1: 33-38. (In Russian, Engl. summary.)

RASHEED S. 1966: Observations on the spiruroid nematodes of fish with a revision of the genus Metabronema Yorke and Maplestone, 1926. Z. Zool. Syst. Evolutionsforsch. 3: 359387.

TAYLOR E.L. 1925: Notes on some nematodes in the Museum of the Liverpool School of Tropical Medicine. II. Ann. Trop. Med. Parasitol. 19: 557-569.

TUBANGUI M.A., MASILUÑGAN V.A. 1938: Nematodes in the collection of the Philippine Bureau of Science, III. Philippine J. Sci. 64 (Year 1937): 257-267.

Yorke W., MAPlestone P.A. 1926: The Nematode Parasites of Vertebrates. J. \& A. Churchill, London, 536 pp. 